\title{
First conclusions about results of GPR investigations in the Church of the Assumption of the Blessed Virgin Mary in Kłodzko, Poland
}

\author{
Anatolii Chernov $^{1}$, Dariusz Dziubacki ${ }^{2}$, Martina Cogoni $^{3}$, and Alexandru Bặdescu ${ }^{4}$ \\ ${ }^{1}$ Institute of Geology, Department of Geophysics, Taras Shevchenko National University of Kyiv, Kyiv, Ukraine \\ ${ }^{2}$ Faculty of Geology, Geophysics and Environmental Protection, Department of Geophysics, AGH University of Science \\ and Technology, Cracow, Poland \\ ${ }^{3}$ Department of Civil Engineering, Environmental Engineering and Architecture, University of Cagliari, Cagliari, Italy \\ ${ }^{4}$ Faculty of Geology and Geophysics, Department of Geophysics, University of Bucharest, Bucharest, Romania
}

Correspondence: Chernov Anatolii (achernovp@gmail.com)

Received: 30 June 2017 - Discussion started: 7 August 2017

Revised: 15 November 2017 - Accepted: 25 November 2017 - Published: 27 March 2018

\begin{abstract}
The article presents results of a ground penetrating radar (GPR) investigation carried out in the Church of the Assumption of the Blessed Virgin Mary in Kłodzko, Poland, dating from the 14th to 16th centuries. Due to the 20th century wars, the current state of knowledge about the history of the church is still poor. Under the floor of the Catholic temple, unknown structures might exist. To verify the presence of underground structures such as crypts and tombs, a GPR survey was carried out in chapels and aisles with 500 and $800 \mathrm{MHz}$ GPR shielded antennas. Numerous anomalies were detected. It was concluded that those under the chapels were caused by the presence of crypts beneath the floor.
\end{abstract}

\section{Introduction}

Significant progress in archaeology was possible thanks to the advancement of the ground penetrating radar (GPR) technology and methodology. GPR is widely used in several scientific fields, such as geology and environmental and civil engineering. In archeology, GPR offers a good image of what could lie underground, e.g. caves, tombs and buried objects. The concept of the GPR is well known. An electromagnetic pulse is directed to the ground. Heterogeneities cause reflections that are detected by a receiver (Annan and Cosway, 1992).
The GPR investigation presented in this paper took place in the Church of the Assumption of the Blessed Virgin Mary in Kłodzko. It is a town in the southwestern part of Poland, which was part of Bohemia from the Middle Ages to the Silesian Wars (Tomaszewska, 2010, pp. 26-27). The first information about a sacral building in this region comes from the 12th century. The current Catholic temple was constructed between the 14th and the 16th centuries. Its founder was Ernest of Pardubitz, the first Archbishop of Prague. In the beginning, it was a Knights Hospitaller property, but later fell under Jesuit management (Broniewski, 1970, pp. 39-44; Sobczyk, 2016). Nowadays the church is administered by the Society of Jesus.

In the church there are the following crypts: below the Chapel of Purgatory, which is immediately adjacent to the north aisle and buried there was the count family Montani of Ullersdorf (Ołdrzychowice Kłodzkie) (Bogacz and Skwerenda, 1998, p. 87); in front of the Main Altar under the floor (the resting place of Ernest of Pardubitz) (Broniewski, 1970, pp. 67-68); below the Altar of St. Francis Xavier in the north nave; and below the south nave. Some of them no longer serve their previous function.

The main sources of information were the sketches of the church presented in Figs. 1 and 2, a few websites and several publications about the history of the church. The current state of knowledge about the temple underground is still poor. The aim of the presented work is to verify the presence of structures under the church floor. 


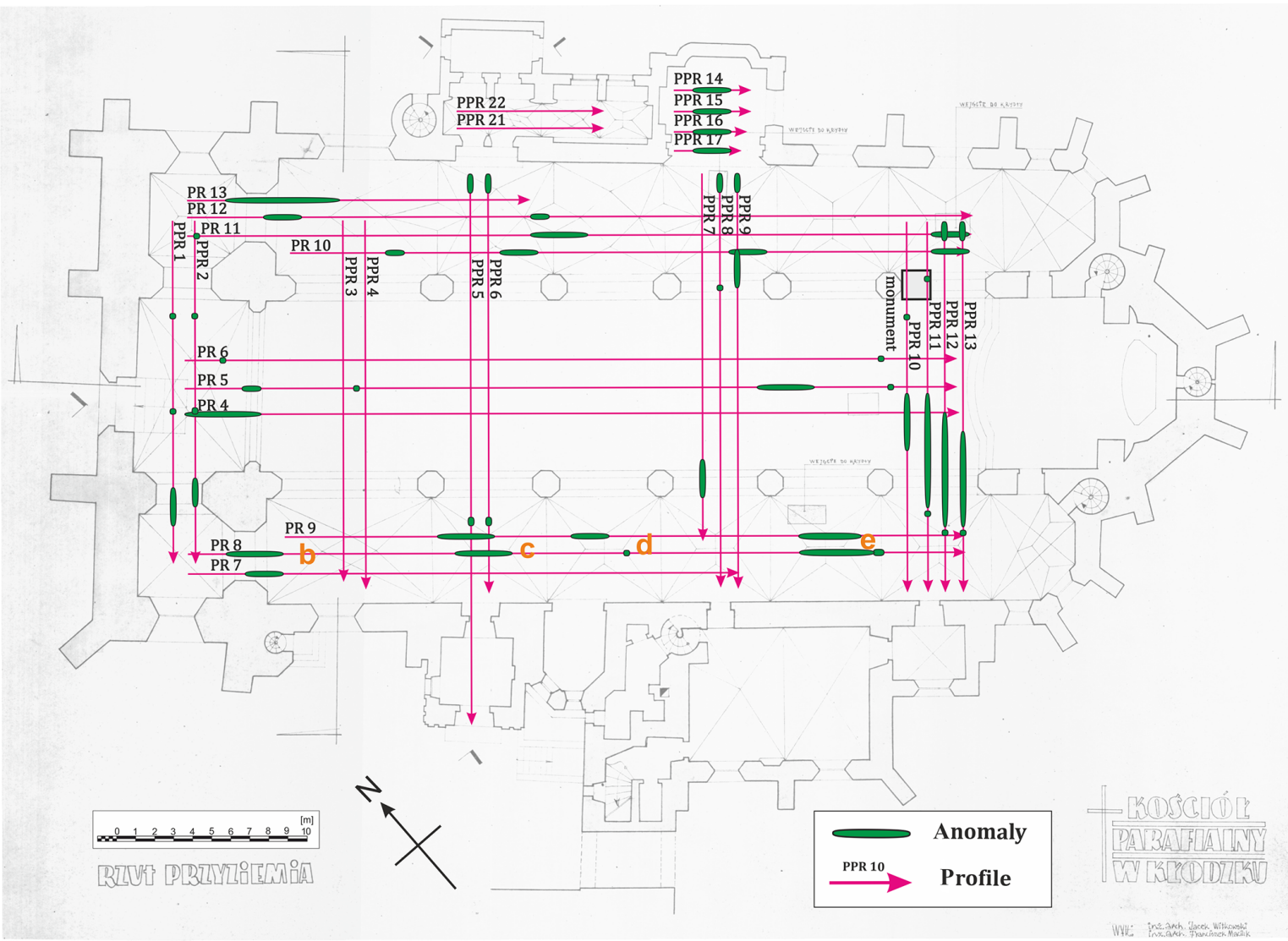

Figure 1. The ground floor plan of the church with the profiles (red) and anomalies (green) set by a $500 \mathrm{MHz}$ antenna. The visualisation is courtesy of the Parish of the Assumption of the Blessed Virgin Mary in Kłodzko, Poland, and Department of Geophysics, AGH UST. It has been modified.
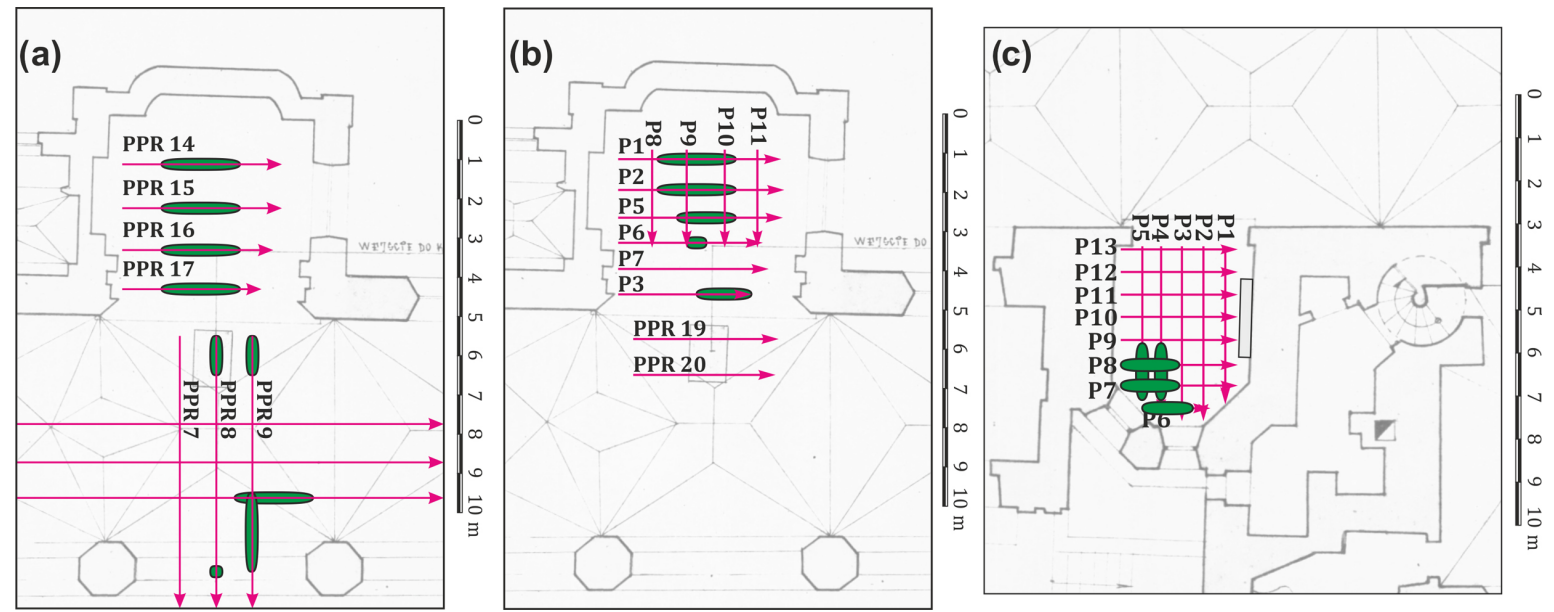

Figure 2. (a) The ground floor plan of the Chapel of Purgatory with the profiles set by a $500 \mathrm{MHz}$ antenna (PPR 14, PPR 15, PPR 16, PPR 17). (b) The ground floor plan of the Chapel of Purgatory with the profiles set by an $800 \mathrm{MHz}$ antenna (P1, P2, P3, P5, P6, P7, P8, P9, P10, P11). (c) The ground floor plan of the Chapel of St. James with the profiles set by an $800 \mathrm{MHz}$ antenna (P1-P5 and P6-P13). The visualisation is courtesy of the Parish of the Assumption of the Blessed Virgin Mary in Kłodzko, Poland, and Department of Geophysics, AGH UST. It has been modified. 


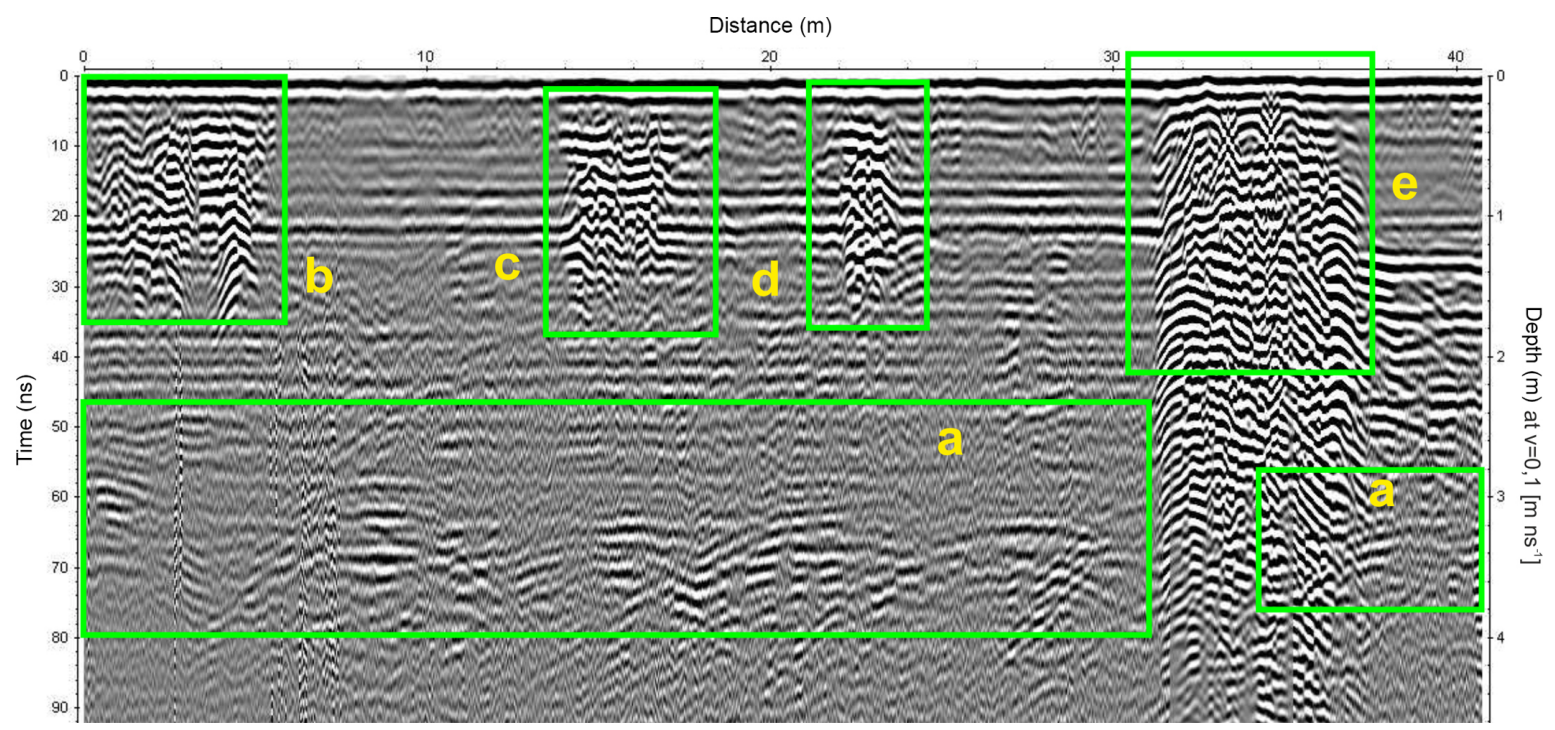

Figure 3. Profile PR 8 and antenna $500 \mathrm{MHz}$.

\section{Acquisition and processing}

The surveys were conducted in aisles and chapels. The radargrams were recorded with a GPR ProEx, produced by MALÅ Geoscience, equipped with 500 and $800 \mathrm{MHz}$ shielded antennas. The velocity for the surrounding medium was established as $0.1 \mathrm{~m} \mathrm{~ns}^{-1}$ (based on similar investigations by Panisova et al., 2016, and a similar processing approach by Persico, 2014, pp. 13-16). The localisation of the profiles in aisles is shown in Fig. 1 (profiles from $500 \mathrm{MHz}$ antenna), in the Chapel of Purgatory in Fig. 2a and b (profiles recorded with a $500 \mathrm{MHz}$ (a) and an $800 \mathrm{MHz}$ (b) antenna). Figure 2c shows the profiles from the Chapel of St. James recorded with an $800 \mathrm{MHz}$ antenna. The floors of the chapels were covered by regular grids of profiles with $0.5-1 \mathrm{~m}$ spacing. The following survey parameters were assumed: for the $800 \mathrm{MHz}$ antenna, the step of measurements was $0.02 \mathrm{~m}$ and the time increment was $0.12 \mathrm{~ns}$; for the $500 \mathrm{MHz}$ antenna, the step of measurements was $0.04 \mathrm{~m}$ and the time increment was $0.2 \mathrm{~ns}$. Anomalies which were detected on the radargrams are shown with the green ovals on the ground floor plans (Figs. 1, 2 ). The processing sequence for the recorded radargrams includes routine steps (Karczewski et al., 2011).

\section{Analysis and interpretation}

\subsection{Aisles}

Several clear hyperbolic anomalies were recorded along the aisles at a time of $50-80 \mathrm{~ns}(2.5-4 \mathrm{~m})$ with both the $500 \mathrm{MHz}$ antenna and the $800 \mathrm{MHz}$ antenna. The shape of the upper part of the reflectors at a time of 50-80 ns $(2.5-4 \mathrm{~m})$ along the aisles resembles the curve of a $15 \mathrm{~m}$ radius circle (in the case of the velocity in the medium of $0.1 \mathrm{~m} \mathrm{~ns}^{-1}$ ), accord- ing to the evaluation of the angle between the branches of the hyperbolic anomalies (e.g. PR 8 in Fig. 3, anomaly "a"). The shallow anomalies (2-20 ns) along the PR 8 profile (at the distances 2-5, 14-18 and 22-24 $\mathrm{m}$ ) are marked in Figs. 1 and 3 (anomalies "b, c, d"). These anomalies were probably caused by the foundations of the pillars (Daniels, 2004, p. 356) or other underground objects. The shallow anomalies and strong reflections at a distance of $32-36 \mathrm{~m}$ are connected with metal objects (like metal grids on the floor) (Figs. 1 and 3 , anomaly "e"). According to the comparison of the data obtained along and across the aisles and the information about the setting of the former church (Broniewski, 1970, p. 39), it can be concluded that the reflections from 50 to $80 \mathrm{~ns}$ might have been caused by the presence of the remains of the foundations of a previous sacral building. Despite the fact that the antennas were shielded, these anomalies might also be interpreted as external reflections, like reflections from the ceiling of the church (the vaults of the naves) (Perrez Garcia, 2004, pp. 335-339), because when we set the velocity at 0.25 to $0.30 \mathrm{~m} \mathrm{~ns}^{-1}$ (the velocity of electromagnetic wave in air) and the radius 0 , the shape of the synthetic hyperbola also resembles the shapes of the anomalies at a depth of 50-80 ns $(2.5-4 \mathrm{~m})$ on the profiles from the aisles.

\subsection{The Chapel of Purgatory}

The radargrams registered with the $500 \mathrm{MHz}$ antenna show a hyperbolic anomaly at $6 \mathrm{~ns}$ (corresponding to a depth of $0.3 \mathrm{~m}$ ). The anomaly is clearly visible on the radargram from the PPR 14 profile (Fig. 4a and b, anomaly " $\mathrm{f}$ "). There is also another reflection visible at $26-32 \mathrm{~ns}(1.2-1.6 \mathrm{~m}$ ) (anomaly "g"). The radargram from the $800 \mathrm{MHz}$ antenna also reveals a clear anomaly at $50 \mathrm{~ns}(2.5 \mathrm{~m})$, which is hardly visible in the data from the $500 \mathrm{MHz}$ antenna (anomaly "h"). Figure 4c 

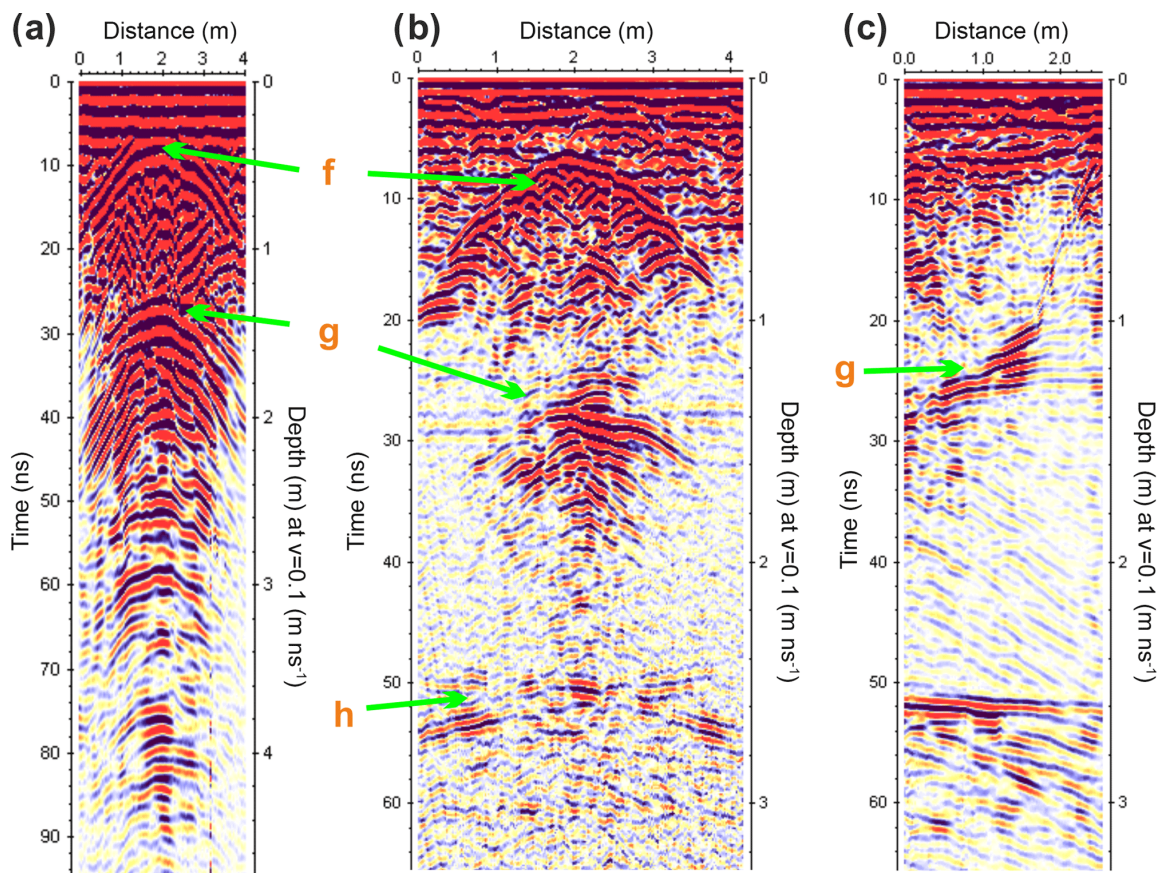

Figure 4. (a) Profile PPR 14 and $500 \mathrm{MHz}$ antenna. (b) Profile P1 and $800 \mathrm{MHz}$ antenna. (c) Profile P9 (perpendicular to profile P1) and $800 \mathrm{MHz}$ antenna.
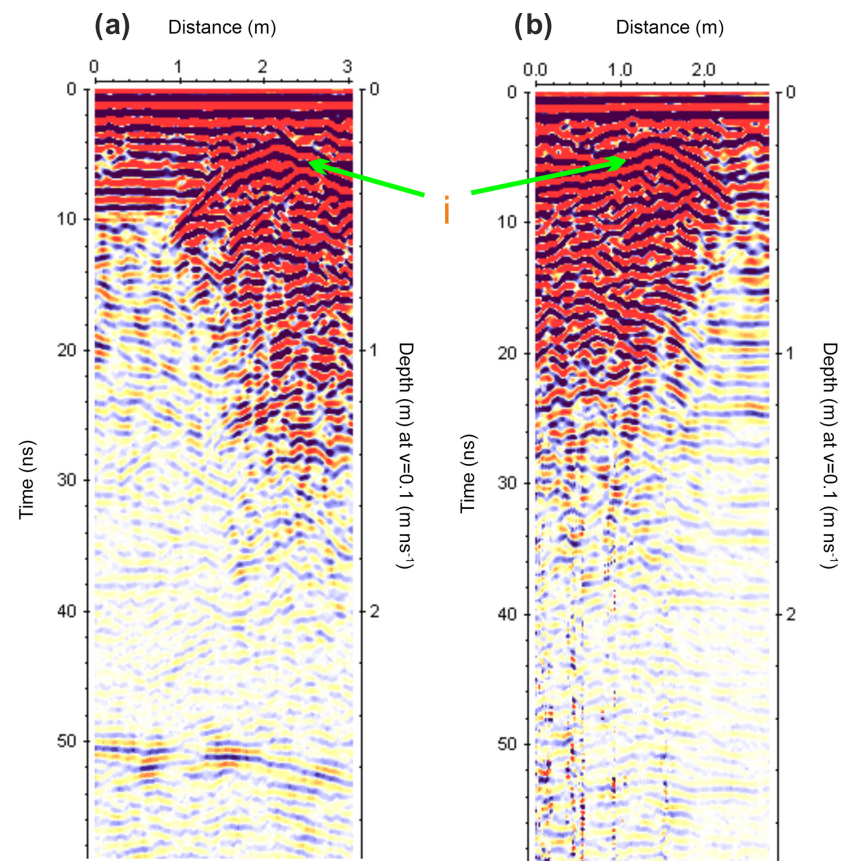

Figure 5. (a) Profile P5 and $800 \mathrm{MHz}$ antenna. (b) Profile P8 and $800 \mathrm{MHz}$ antenna.

shows the radargram obtained along the $\mathrm{P} 9$ profile, which is perpendicular to the P1 (Fig. 4b). The deepest reflection at time $50 \mathrm{~ns}$ is still visible. The reflection at $26 \mathrm{~ns}$ continues from the beginning to the end of the profile with changing depth.

The hyperbolic anomaly at $6 \mathrm{~ns}$ is interpreted as a reflection from the ceiling (vault) of the crypt. It is the most probable interpretation of this anomaly. Crypts and tombs are common in medieval Catholic temples. In this church, there are various crypts and entrances to them are marked on the ground floor plan. Under the PPR 19 and the PPR 20 profiles in Fig. $2 b$ the entrance to the crypt is marked. The recorded crypt is probably a place where the family Montani of Ullersdorf were buried. The localisation of the anomaly suggests that the crypt may continue under the altar. Underneath the anomaly " $\mathrm{f}$ ", there is another reflection visible at time $26 \mathrm{~ns}$ (anomaly "g"). Its shape may be classified by velocity pullup (Conyers, 2012, pp. 171-175) and can be interpreted as the crypt floor. Velocity pull-up is a phenomenon which appears on a radargram when an electromagnetic wave meets a high-velocity medium surrounded by a low-velocity one. Reflections from the velocity boundary at the bottom of the anomaly are pulled up. This explanation implies quite a large size of the crypt (even $3 \mathrm{~m}$ in height). The shape of the reflection at $26 \mathrm{~ns}$ also suggests that it might be connected with the entrance to the crypt in front of the chapel, which is justified because in Fig. 4c it appears at different times. In this case, it may be treated as a reflection from stairs to the crypt. The deepest anomaly from $50 \mathrm{~ns}$ could be defined as external reflections. Another possible interpretation is that these might be the remains of the previous church. 
Probable dimensions of the detected crypt are $3-4 \mathrm{~m}$ in width and $2.4-3 \mathrm{~m}$ in height. The velocity of the electromagnetic wave in the crypt $\left(0.3 \mathrm{~m} \mathrm{~ns}^{-1}\right)$ is three times higher than the velocity in the ground, so the apparent height of the crypt presented on the radargram (Fig. 4a, b) is different $(0.8-1 \mathrm{~m})$ because the value $0.1 \mathrm{~m} \mathrm{~ns}^{-1}$ was applied as the average velocity for the radargram. Therefore, it was assumed that the crypt is filled with air.

\subsection{Chapel of St. James}

A hyperbolic anomaly at $4 \mathrm{~ns}(0.2 \mathrm{~m})$ is visible on the radargrams from this chapel (Fig. 5a and b, anomaly "i"). The difference between similar anomalies (at $6 \mathrm{~ns}$ from the Chapel of Purgatory) is that directly under the main reflection there are many smaller disturbances. Like in the Chapel of Purgatory, reflections at $50 \mathrm{~ns}$ are visible.

The main hyperbolic reflection at a time of $4 \mathrm{~ns}$ is interpreted as the vault of a crypt (Fig. 5a, b). The changes in the shape of the anomaly are associated with the direction of the profiles. The vault can be described as a barrel or pointed barrel vault (Imposa and Grassi, 2015; Barilaro et al., 2007). In that case, on the profiles crossing perpendicularly to its stretch a hyperbolic anomaly was detected (Fig. 5a). The radargrams collected parallel to the stretch of the vault showed flat reflections (Fig. 5b) because the shape of the crypt ceiling was flattened under them.

The probable size of the crypt is $2 \mathrm{~m}$ in width. The crypt is a newly discovered underground object. Because of the shape and location of the anomaly, the expected entrance to the tomb is outside the chapel.

It should be mentioned that our results were compared with similar surveys that had been conducted in the Church of St. George (Panisova et al., 2016). The researchers evaluated the same velocity for the underground medium as we did: $0.1 \mathrm{~m} \mathrm{~ns}^{-1}$. They detected the reflection corresponding to the upper part of the crypts at $10 \mathrm{~ns}$ (our 4-6ns) and 20$24 \mathrm{~ns}$ (possibly our $26 \mathrm{~ns}$ ) to the lower part.

\section{Conclusions}

As a result of the investigation carried out in the church in Kłodzko, two crypts were detected just beneath chapels floors. Their location and size were estimated. The position of the crypt in the Chapel of St. James suggests that its entrance may be outside the church. The complexity of the radargram image from the Chapel of Purgatory gives rationale to the hypothesis that the entrance marked on the church sketches leads to this crypt. What is more, the crypt may continue under the altar in the chapel.

The majority of the radargrams recorded along the profiles in the aisles and chapels include hyperbolic anomalies at a time of 50-80 ns (2.5-4 m). They are probably the effect of electromagnetic wave diffraction. In that case, two explana- tions are proposed. The first one is that their origin is probably connected with the remains of the previous church; the other one is that these are the diffraction points on the ceiling of the Catholic temple (external reflections).

This research might be helpful for future investigations, especially archeological excavations and restoration works.

Results of the survey proved that a better vertical resolution could be obtained with an $800 \mathrm{MHz}$ antenna than with a $500 \mathrm{MHz}$ antenna.

Data availability. GPR data presented in the work were collected by authors of the publication during SEG Field Camp 2016 together with another participants of the event. The data are the property of SEG Student Chapter Cracow and are available on request.

Church sketches were made available by the Parish of the Assumption of the Blessed Virgin Mary, Kłodzko, and Department of Geophysics, AGH. Authors made modifications to the images. Original unmodified figures are the property of the Roman Catholic Parish of the Assumption of the Blessed Virgin Mary. Access to them is limited and special permission is required.

Competing interests. The authors declare that they have no conflict of interest.

Acknowledgements. The authors would like to express their gratitude to the Society of Exploration Geophysicists, TGS, the organisers of SEG Field Camp 2016 (SEG Student Chapter Cracow and SEG Bucharest Student Chapter). The authors are grateful to COST (European Cooperation in Science and Technology) Action TU1208 "Civil engineering applications of Ground Penetrating Radar" (www.cost.eu, www.GPRadar.eu) for fostering and supporting cooperation among different countries. The authors thank the COST Action for giving them the opportunity to present the results of the investigation during the European Geosciences Union (EGU) General Assembly 2017. The authors would like to express their deepest gratitude to Jerzy Ziętek and Anna Strzępowicz, from the AGH University of Science and Technology, for their support during the investigation and sketches preparation. Special thanks are also due to Father Robert Mól, parish priest of the Parish of the Assumption of the Blessed Virgin Mary in Kłodzko, and Michał Kurzej from Jagiellonian University for valuable help regarding historical information about the church.

Edited by: Lev Eppelbaum

Reviewed by: Lara Pajewski and one anonymous referee

\section{References}

Annan, A. P. and Cosway, S. W.: Ground Penetrating Radar Survey Design, Symposium on the Application of Geophysics to Engineering and Environmental Problems, 1992, 329-351, https://doi.org/10.4133/1.2921946, 1992.

Barilaro, D., Branca, C., Gresta, S., Imposa, S., Leone, A., and Majolino, D.: Case study. Ground penetrating radar (G.P.R.) 
surveys applied to the research of crypts in San Sebastiano's church in Catania (Sicily), J. Cult. Herit., 8, 73-76, https://doi.org/10.1016/j.culher.2006.10.003, 2007.

Bogacz, T. and Sakwerda, J.: Czasy Nowożytne (XVI-XVIII w), in: Kłodzko - dzieje miasta, edited by: Gładkiewicz. R., Muzeum Ziemi Kłodzkiej, Kłodzko, 1998.

Broniewski, T.: Kłodzko, in: Śląsk w Zabytkach Sztuki, edited by: Broniewski, T., Zlata, M., 2nd Edn., Ossolineum, Wrocław, 1970.

Conyers, B. L.: Interpreting Ground-penetrating Radar for Archeology, 1st Edn., Left Coast Press, Walnut Creek, 2012.

Daniels, D. J. (Ed.): Fountains Abbey, in: Ground Penetrating Radar, 2nd Edn., Vol. 1, The Institution of Electrical Engineers, London, 2004.

Karczewski, J.: Procedury do przetwarzania danych georadarowych, in: Zarys metody georadarowej, edited by: Koch, M., 2nd Edn., Wydawnictwo AGH, Cracow, 2011.

Imposa, S. and Grassi, S.: Georadar survey inside the Santa Maria Maggiore church of Ispica (Sicily-Italy), Environ. Earth. Sci., 73, 1939-1949, https://doi.org/10.1007/s12665-014-3542-9, 2015.
Panisova, J., Murín, I., Pašteka, R., Haličková, J., Brunčák, P., Pohánka, V., Papčo, J., and Milo, P.: Geophysical fingerprints of shallow cultural structures from microgravity and GPR measurements in the Church of St. George, Svätý Jur, Slovakia, J. Appl. Geophys., 127, 102-111, https://doi.org/10.1016/j.jappgeo.2016.02.009, 2016.

Pérez Gracia, V.: Clutter in radar data caused by reflections from external anomalies, in: Ground Penetrating Radar, edited by: Daniels, D. J., 2nd Edn., Vol. 1, The Institution of Electrical Engineers, London, 2004.

Persico, R.: Introduction to ground penetrating radar, John Wiley \& Sons, Inc., Hoboken, New Jersey, 13-16, 2014.

Sobczyk, D.: Arnošt of Pardubice in the local memory of Kłodzko, Melusine: old literature and culture, 2, 49-59, https://doi.org/10.18276/me.2016.2-04, 2016.

Tomaszewska, G.: Kłodzka fara : Kościół Wniebowzięcia Najświętszej Marii Panny w Kłodzku, Kłodzkie Towarzystwo Oświatowe, Wydawnictwo "Maria”, Kłodzko - Nowa Ruda, 2010. 